\title{
Penerapan Metode Empati dalam Mendesain Terapi Anak Autis menggunakan Dolphin Assisted Therapy
}

\author{
Anastasya Putri Yusuf dan Defry Agatha Ardianta \\ Departemen Arsitektur, Fakultas Teknik Sipil dan Perencanaan, Institut Teknologi Sepuluh Nopember (ITS) \\ e-mail: agathadefry@arch.its.ac.id
}

\begin{abstract}
Abstrak-Dewasa ini banyak arsitektur yang tidak hanya menempatkan manusia saja sebagai subjek desainnya, melainkan juga hewan. Namun seringkali desain arsitektural hanya memperhatikan kebutuhan manusia saja, kurang mempertimbangkan perilaku hewan yang statusnya juga sebagai pengguna. Arsitektur seharusnya dapat berlaku adil kepada setiap subjek desainnya. Yang dimaksud dengan 'adil' adalah merancang dengan mempertimbangkan karakteristik setiap subjek desainnya lalu merangkumnya menjadi sebuah arsitektur yang tepat bagi setiap subjek di dalamnya. Dalam terapi anak autis menggunakan Dolphin Assisted Therapy (DAT), hewan tidak hanya menjadi objek namun juga subjek yang membantu kesembuhan pasien. Untuk mengakomodasi kebutuhan setiap pengguna dalam desain, digunakan metode Empati dimana perancang menempatkan diri sebagai user guna memahami perspektif ruang dari sudut pandang user. Hal ini dilakukan agar mengurangi subjektifitas perancang dalam mendesain dan guna menciptakan desain yang tepat bagi setiap user di dalam arsitektur tersebut.
\end{abstract}

Kata Kunci-Adil, Anak Autis, Dolphin Assisted Therapy, Empati.

\section{PENDAHULUAN}

$\mathrm{D}$ ALAM Lectures on Ethics, Kant menegaskan bahwa manusia memiliki kewajiban tidak langsung terhadap hewan, bukan kewajiban terhadap mereka, melainkan berkaitan dengan mereka sejauh perlakuan manusia terhadap hewan dapat memengaruhi kewajiban manusia sebagai manusia [1]. Sehingga arsitektur yang secara sengaja melibatkan hewan sudah selayaknya mempertimbangkan hewan dalam desain sama baiknya dengan pertimbangan terhadap manusia. Seringkali fungsi dan skala tidak sesuai dengan kemampuan hewan. Sehingga dalam mendesain ruang untuk interaksi manusia-hewan, etologi (ilmu perilaku hewan) dan skala harus dipelajari sebagai faktor penentu desain. Konfigurasi ruang menjadi katalis untuk interaksi dalam arsitektur. Dalam DAT, interaksi manusia dengan hewan sangatlah krusial, serta hewan tidak hanya menjadi objek namun sebagai subjek yang memengaruhi kesembuhan pasien. Hasil yang diharapkan adalah terciptanya kesetaraan peran arsitektur terhadap manusia dan hewan.

Terapi lumba-lumba dalam artikel ini digunakan untuk terapi Autis. Autis adalah gangguan perkembangan saraf yang memengaruhi kemampuan anak dalam berkomunikasi, interaksi sosial, dan perilaku. Berdasarkan data dari Badan Pusat Statistik, di Indonesia diperkirakan ada sekitar 1 anak autis dalam 100 bayi yang lahir.

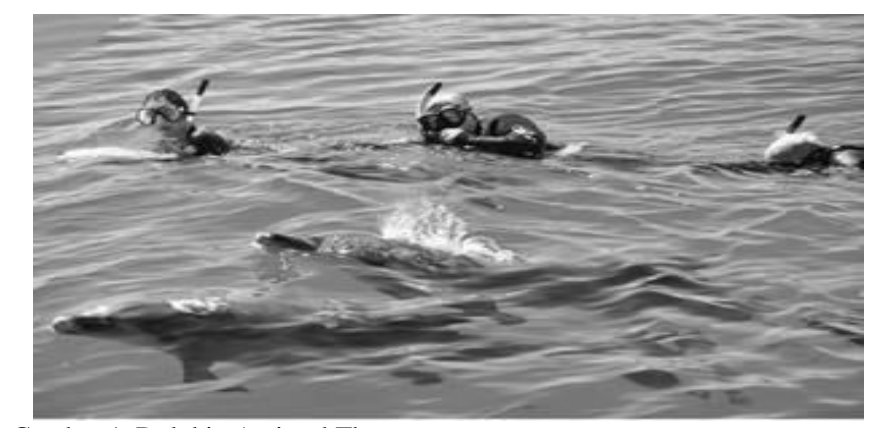

Gambar 1. Dolphin Assisted Therapy.

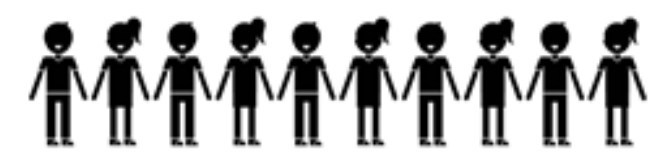

Gambar 2. Jumlah maksimal pasien dalam 1 sesi terapi.

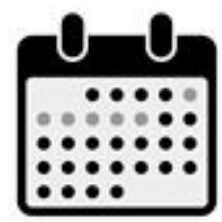

Gambar 3. Durasi 1 sesi rangkaian terapi.

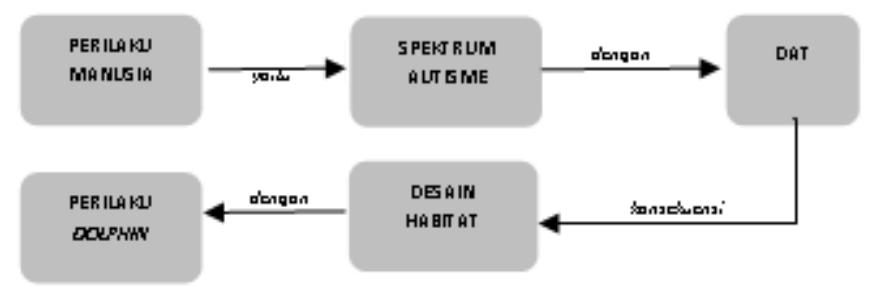

Gambar 4. Diagram sebab-akibat.

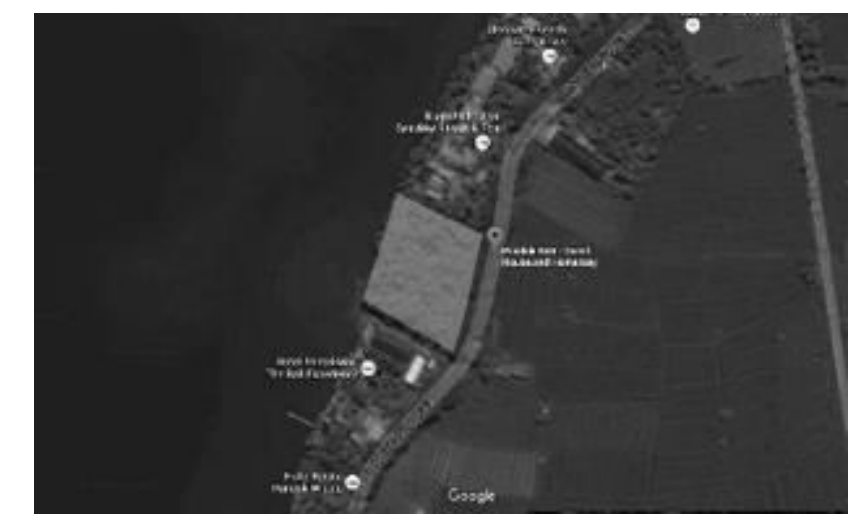

Gambar 5. Lokasi lahan 


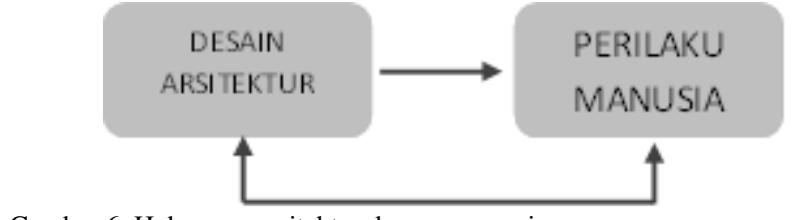

Gambar 6. Hubungan arsitektur dengan manusia
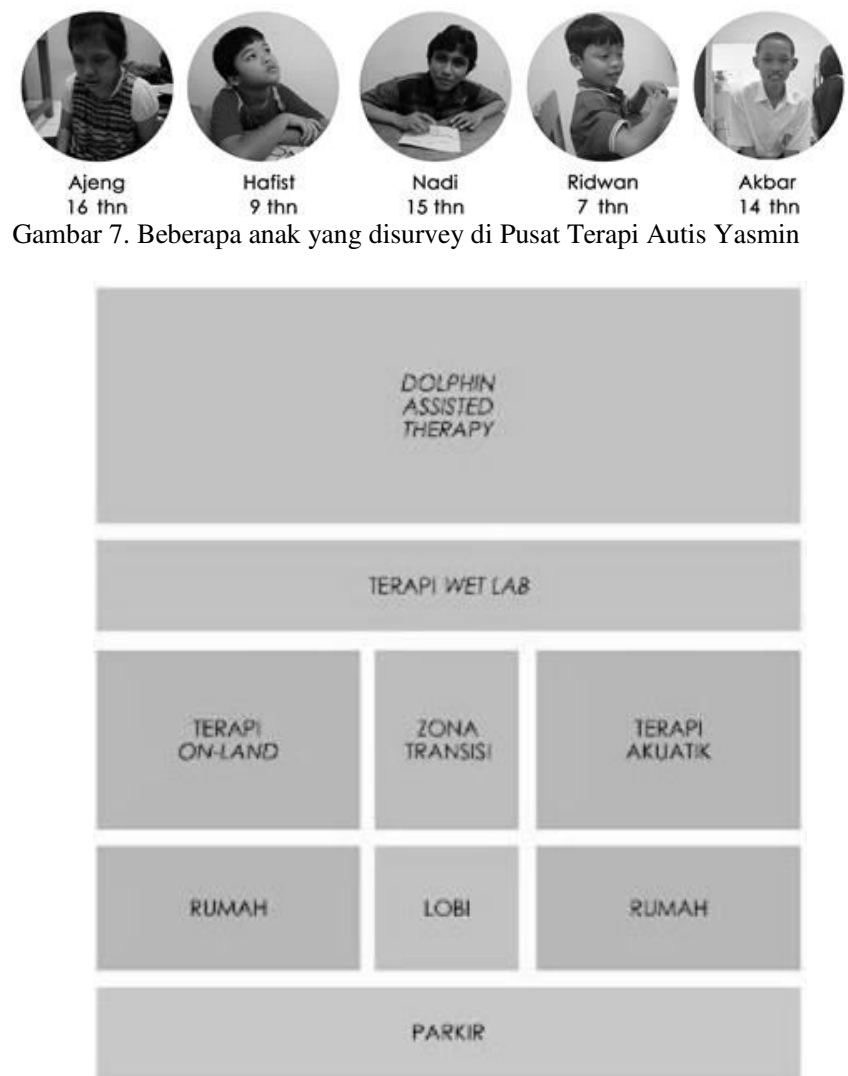

Gambar 8. Sekuensi spasial

Tujuan utama DAT adalah mempertemukan pasien dengan lumba-lumba dan mengizinkan pasien berenang bersama. DAT dilengkapi dengan beberapa rangkaian terapi lainnya. Interaksi dengan lumba-lumba berguna memperkuat dan memperlancar proses pembelajaran kognitif, fisik, atau respon sosial-emosional.

Kajian ini mencoba mengeksplorasi hubungan antara hewan dengan manusia serta bagaimana mengakomodasi keduanya dalam desain secara setara. Aspek persepsi ruang oleh pengguna dipelajari guna menentukan desain yang sesuai, dan ini berarti juga mempelajari persepsi lumba-lumba di dalam ruang guna menyediakan habitat yang sesuai [2].

Berdasarkan analisa lokasi terhadap populasi lumba-lumba, kepadatan penduduk, dan akses terhadap lahan, dapat disimpulkan bahwa lokasi yang paling tepat adalah Pantai Lovina, Bali. Tepatnya di Temukus, Kecamatan Banjar, Kabupaten Buleleng.

\section{PENDEKATAN DAN METODE DESAIN}

\section{A. Pendekatan Desain}

Pendekatan yang digunakan adalah pendekatan perilaku.

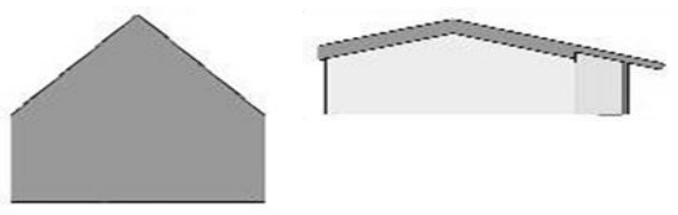

Gambar 9. Siluet bangunan
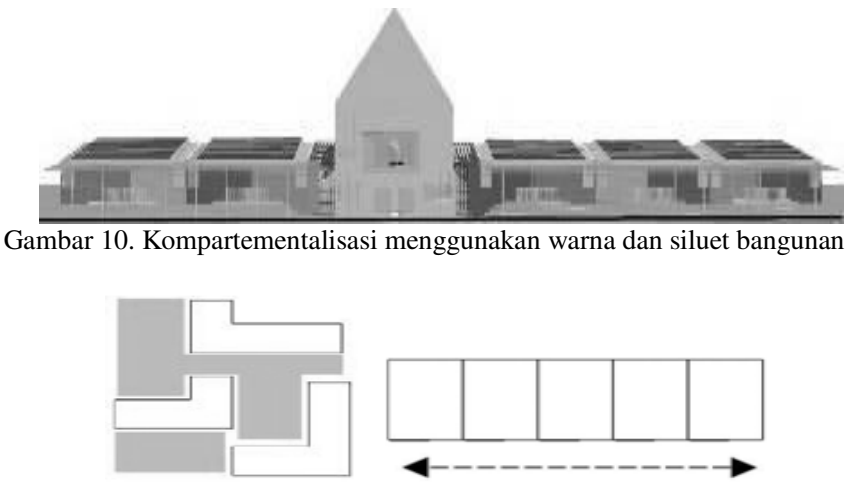

Gambar 11. Variasi susunan unit.

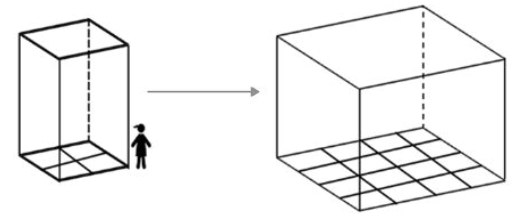

Gambar 12. Kebutuhan spasial anak autis

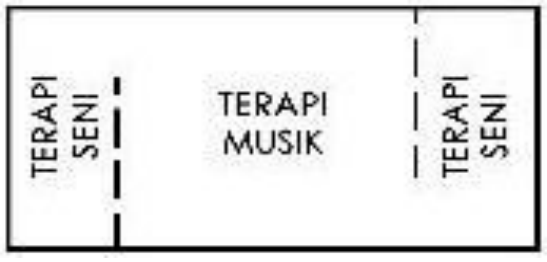

Gambar 13. Modul ruang terapi.

Teori behaviorisme menganalisa perilaku yang tampak, dapat diukur, dilukiskan dan diramalkan. Behaviorisme ingin mengetahui bagaimana perilaku suatu organisme dikendalikan oleh faktor-faktor lingkungan. Memandang setiap organisme sebagai makhluk reaktif yang memberi respon terhadap lingkungannya. Sebuah arsitektur dibangun untuk memenuhi kebutuhan manusia. Dan dari arsitektur itulah muncul kebutuhan manusia yang baru kembali [3].

\section{B. Metode Desain}

Metode yang dipakai adalah metode Empati. Desain empatik mencoba memenuhi kebutuhan user dan memikirkan apa yang dibutuhkan demi membuat hidup user lebih mudah. Desain empatik bertujuan membangun hubungan emosional antara user dan arsitektur dengan memahami lebih baik mengenai pengalaman dan kebutuhan user. Agar sebuah produk menjadi efektif, haruslah memenuhi kebutuhan fungsional dan emosional individu, serta user perlu merasa bahwa produk tersebut dirancang 'hanya untuk mereka'. Hal tersebut dapat dicapai melalui sejumlah cara, seperti mengajukan pertanyaan terkait perilaku pengguna melalui wawancara, penelitian, observasi, atau penelusuran referensi yang merinci. 


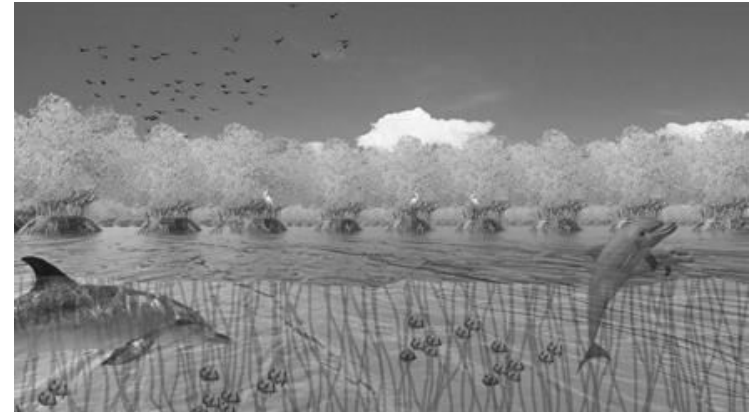

Gambar 14. Habitat lumba-lumba

\section{PENERAPAN KONSEP}

Sekuensi spasial keseluruhan area desain diorganisasi dalam tatanan yang logis berdasarkan jadwal penggunaan ruang. Hal ini disebabkan afinitas anak autis terhadap prediktabilitas dan rutinitas. Ruang mengalir secara halus melalui sirkulasi searah agar memudahkan navigasi dari satu area ke area lainnya. Sekuensi spasial tersebut juga dikombinasikan dengan zonasi sensori. Zonasi sensori sangat berpengaruh terhadap anak autis dalam tingkah laku mereka. Zonasi sensori didesain dengan mengombinasikan kelima indera. Satu unit didesain dengan kualitas sensori yang konsekuen. Rumah pasien, terapi akuatik dan terapi on-land termasuk dalam stimulus rendah. Sedangakan lobi, terapi wet-lab, dan DAT adalah stimulus tinggi. Zona transisi diletakkan di tengah agar menjadi titik peralihan dari stimulus tinggi ke rendah ataupun sebaliknya. Pada zona transisi diletakkan sebuah node yang mengindikasikan perubahan.

Konsep besar desain ini adalah "homey", agar anak merasa nyaman selama menjalankan proses terapi meskipun di lingkungan baru. Persepsi terhadap rumah digeneralisasi. Massa bangunan diadaptasi dari geometri dasar kotak dan bentuk rumah pada umumnya yang bersudut pada bagian atap. Siluet seperti ini dihadirkan agar anak dapat menganggap tempat ini layaknya rumahnya sendiri. Keseluruhan desain sebisa mungkin dibuat low-rise building.

Kompartementalisasi adalah usaha untuk membatasi limit sensori suatu area/unit. Guna kemudahan sang anak untuk wayfinding maka desain dibagi menjadi kompartemenkompartemen. Setiap unit/kompartemennya harus mencakup fungsi yang jelas dan memiliki kualitas sensori yang konsekuen. Hal ini guna menentukan dan membatasi lingkungan sensori dari setiap aktivitas. Variasi konfigurasi unit diantaranya, dipecah dan paralel. Susunan unit yang dipecah menciptakan courtyard yang dapat memicu interaksi. Anak autis cenderung anti sosial dan memiliki dunianya sendiri, karenanya dibutuhkan desain yang dapat memicu interaksi soisal. Sedangkan susunan paralel dibuat untuk membentuk kontinuitas yang menerus. Perlu diperhatikan dalam susunan paralel ini, ruang yang terjadi tidak boleh terlalu kecil dan lurus karena akan memicu keinginan untuk berlari.

Dalam mendesain untuk anak autis dan lumba-lumba, kebutuhan spasial masing-masing sangatlah penting. Untuk

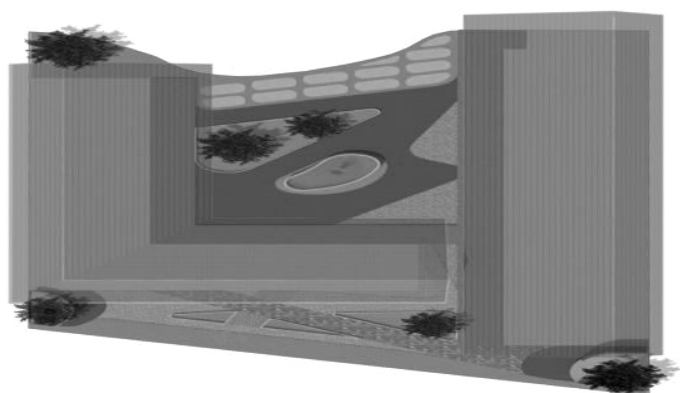

Gambar 15. Area terapi on-land.

kebutuhan spasial seorang anak autis, terdapat peningkatan $450 \%$ dari anak normal. Serta sirkulasi ideal adalah 38\%. Sedangkan untuk lumba-lumba, minimal diameter kolam untuk 1 lumba-lumba adalah 15m. Hal-hal tersebut dijadikan dasaran dalam menentukan luas ruangan.

Untuk memperkenalkan sang anak terhadap kehidupan bermasyarakat, diterapkan konsep flexible yet rigid di dalam desain konfigurasi ruangan. Ruang didesain memiliki modul yang fixed namun di interiornya terdapat dinding partisi yang dapat mengubah fungsi ruang tersebut secara terjadwal.

Kolam lumba-lumba mengambil tempat di bagian laut. Kolam lumba-lumba dirancang dengan setting yang dinamis dan dilengkapi dengan stimulus alami seperti, air laut alami, tanaman laut, ikan-ikan kecil serta terumbu karang. Batas ruang antara kolam kecil dan besar menggunakan breakwater mangrove. Breakwater ini selain sebagai pemecah ombak, juga dapat meningkatkan keanekaragaman hayati di dalam laut.

\section{KESIMPULAN/RINGKASAN}

Arsitektur tidak hanya milik manusia, akan tetapi sebagai wadah semua makhluk hidup untuk beraktivitas. Oleh karenanya arsitektur harus mampu mengakomodir kebutuhan setiap subjek pengguna di dalamnya. Karena setiap makhluk hidup memiliki hak untuk mendapatkan pertimbangan moral. Arsitektur sudah sepantasnya berlaku adil kepada setiap subjek desainnya. Kini arsitektur mulai bergerak ke arah yang lebih jauh lagi, dari eco-friendly menuju animal-friendly. Karena manusia dan hewan adalah sama-sama makhluk hidup yang berhak mendapatkan pertimbangan moral. Perancang yang baik tidak lagi hanya sekedar mempertimbangkan desain bangunan dan estetikanya, melainkan makna dibalik desain tersebut. Maka dari itu mempelajari karakteristik subjek yang di desain sangatlah penting, agar dapat menghasilkan arsitektur yang tepat guna.

\section{DAFTAR PUSTAKA}

[1] I. Kant, Lectures on Ethics. Cambridge: Cambridge University Press.

[2] N. Naing, Model of Structuring Settlement on the Wa-ter Coastal of Ternate. 2013.

[3] Tandal and Egam, "Arsitektur Berwawasan Perilaku," Media Matrasain, vol. 8,2011 . 